\title{
Revascularization After Traumatic Spinal Cord Injury
}

\begin{abstract}
Chun Yao, Xuemin Cao and Bin Yu*
Key Laboratory of Neuroregeneration of Jiangsu and Ministry of Education, Co-innovation Center of Neuroregeneration, NMPA Key Laboratory for Research and Evaluation of Tissue Engineering Technology Products, Nantong University, Nantong, China
\end{abstract}

Traumatic spinal cord injury (SCl) is a complex pathological process. The initial mechanical damage is followed by a progressive secondary injury cascade. The injury ruptures the local microvasculature and disturbs blood-spinal cord barriers, exacerbating inflammation and tissue damage. Although endogenous angiogenesis is triggered, the new vessels are insufficient and often fail to function normally. Numerous blood vessel interventions, such as proangiogenic factor administration, gene modulation, cell transplantation, biomaterial implantation, and physical stimulation, have been applied as SCl treatments. Here, we briefly describe alterations and effects of the vascular system on local microenvironments after SCl. Therapies targeted at revascularization for SCl are also summarized.

Keywords: spinal cord injury, blood vessel, nerve regeneration, therapeutic interventions, angiogenesis

\section{INTRODUCTION}

Traumatic injury to the spinal cord activates several complex pathological events, resulting in physical disability, psychological devastation, and social burdens (Hutson and Di Giovanni, 2019). Nerve tissues are damaged after spinal cord injury (SCI) with motor and sensory neuron dysfunction. Although the injured nerve tissues can undergo repair, the regeneration is limited and usually hypofunctional. Thus, there is an urgent need for interventions that effectively promote axon regeneration and functional recovery after SCI (Oudega, 2012). The acute SCI includes two phases, the primary mechanical destruction (immediate effect of trauma) and a later secondary injury (occurring over a time course from minutes to weeks; Silva et al., 2014). A cascade of progressive damages occurs in the lesion, such as vascular disruption, inflammation, demyelination, and apoptosis, leading to glial scar and cavity formation (Fleming et al., 2006; Garcia et al., 2016).

As mentioned, blood vessels that play a crucial role in nerve regeneration and functional recovery are ruptured. The mechanical forces destroy not only neural cells (neurons, astrocytes, and oligodendrocytes) but also blood vessels around the injury epicenter. In addition, the blood-spinal cord barrier (BSCB) in the surrounding tissues has increased permeability. This destruction induces ischemia and inflammation, which further exacerbates the overall tissue damage (Haggerty et al., 2018). Although new blood vessels form in the lesion, this angiogenesis is insufficient. Hence, understanding the vascular responses in the lesion microenvironment after SCI is of great importance. Interventions modulating vascular responses to promote sufficient functional vessel formation are needed for SCI therapy (Ng et al., 2011). To date, 
multiple treatments for blood vessel interventions in SCI have been developed, including proangiogenic factor administration, gene modulation, cell transplantation, biomaterial implantation, and physical stimulation. This review will provide an extensive overview of the vascular alterations after SCI and summarize current attempts to repair SCI using blood vessel interventions.

\section{VASCULAR RESPONSES AFTER SPINAL CORD INJURY}

The vascular system consists of interconnected endothelial cell tubules and is a highly branched and hierarchically ordered network, similar to the nervous system (Serini and Bussolino, 2004). In normal conditions, the blood vessels transport ingredients (oxygen, nutrients, and hormones), remove metabolic waste and facilitate cell circulation, which provides a supportive microenvironment for the nervous system (Adams and Eichmann, 2010; Himmels et al., 2017). Anatomically, there is a higher density of capillary beds in the gray matter than in the white matter, and this may be to meet the greater demand for metabolic activity in neuronal cells within the gray matter (Haggerty et al., 2018).

Several phases of repair occur in the microenvironment of the lesion after SCI. These responses include regenerationassociated gene expression, axonal sprouting, oligodendrocyte remyelination, and endogenous angiogenesis. However, the effectiveness of this repair is limited (Hagg and Oudega, 2006). Glial scars, inflammation, growth-inhibitory molecules, and blood vessel disruption contribute to the hostile microenvironment at the injury sites, hindering axon regeneration and functional recovery (Silva et al., 2014; Tran et al., 2018). The initial mechanical force causes immediate local vascular damage and BSCB breakdown that increases vascular permeability. The ensuing ischemia and immune cell infiltration accelerate secondary anatomical damage and neurological deficits. As a response to decreased vessel density, endogenous angiogenesis and vascular remodeling take place around the lesion.

\section{Blood Vessel Rupture and Hemorrhage}

Under healthy conditions, vessels and astrocytic processes associate closely to form the perivascular basement membrane (BM). With injury, mechanical trauma ruptures local microvasculature structure and disconnects blood vessels with astrocytes. The blood vessel wall then separates from the $\mathrm{BM}$ into an inner endothelial and an outer parenchymal part (Takigawa et al., 2010). There is a dramatic endothelial cell (EC) loss due to necrosis that occurs within the first $24 \mathrm{~h}$ after the insult. Then, in the following days, ECs undergo apoptosis induced chiefly by ischemia. Detachment from the extracellular matrix (ECM) surrounding the blood vessels also contributes to EC loss (Casella et al., 2002; Oudega, 2012). Blood vessel density around the lesion continues to decrease. Structurally altered BMs further exacerbate the expansion of inflammation during the subacute phase of
SCI. Cellular debris from the disrupted vascular architecture is harmful to nearby neural cells, aggravating cell death. In the meantime, hemorrhaging occurs at lesion sites. The bleeding accelerates thrombin formation and increases extracellular glutamine levels, red blood cell lysis, and iron toxicity, which together exacerbate axonal damage (Losey et al., 2014). Hemorrhaging occurs chiefly within the gray matter and later extends radially into adjacent white matter (Tator and Koyanagi, 1997; Losey et al., 2014). Injection of bacterial collagenase, which minimizes mechanical injury, has shown that the induced hemorrhaging is associated with BSCB disruption, leukocyte recruitment, and axonal damage, leading to secondary injury and poor neurological outcomes after SCI (Losey et al., 2014).

\section{BSCB Disruption}

The blood-spinal cord barrier (BSCB), a tight barrier between the blood and spinal cord tissues, assists in maintaining spinal cord homeostasis (Sharma, 2005; Yu et al., 2016a). The tight junction proteins, vascular basal lamina, astrocyte end-feet processes, and pericytes comprise the basal molecular structure of BSCB, similar to that of the blood-brain barrier (Huber et al., 2001). The initial mechanical injury force, combined with compression or vascular dilation-induced shear stress, disrupt the neurovascular unit and membrane structure (Oudega, 2012; Jin et al., 2021). Injury-induced pro-inflammatory cytokines (such as TNF $\alpha$ and IL-1 $\beta$ ), vasoactive substances (such as reactive oxygen species, nitric oxide, and histamines), and matrix metalloproteinases (MMPs) elevate vascular permeability (Donnelly and Popovich, 2008). The BSCB disruption rapidly occurs in the first several hours. This abnormal permeability of BSCB is apparent during angiogenesis, which proceeds during a period of 3-7 days post-injury (Whetstone et al., 2003). The hyper-permeability of BSCB further damages local blood vessels. Immune cells, such as lymphocytes, neutrophils, and monocytes, infiltrate into the lesion site, leading to inflammatory responses. Calcium, excitatory amino acids, free radicals, and inflammatory mediators also pass into the injury site, contributing to secondary injury after SCI (Ng et al., 2011).

\section{Blood Supply/Ischemia}

Traumatic injuries also affect spinal cord blood supply, which is closely correlated with the severity of damage (Martirosyan et al., 2011). The degenerated ECs sever local vascular networks, aggravating ischemia. The lack of adequate blood supply induces apoptosis and death of neural cells in the lesion epicenter (Figley et al., 2014; Losey et al., 2014). Hence, this reduction in blood flow leads to further tissue loss. Reduced blood pressure also decreases microvascular blood flow, accelerating organ dysfunction (Guha et al., 1989). Restoring blood supply around lesion sites is pivotal for SCI repair. Vascular smooth muscle cells (vSMCs) and pericytes around vessels coordinate to control blood flow into the central nervous system. It has been conclusively demonstrated by $\mathrm{Li}$ et al. that pericytes on capillaries caudal to the lesion abundantly express a vasoconstriction-relevant enzyme. Treatments that 
dilate vessels and improve blood flow facilitate functional recovery after SCI (Li et al., 2017).

\section{Endogenous Angiogenesis}

Briefly, there are three main blood vessel formation mechanisms: vasculogenesis, splitting angiogenesis, and sprouting angiogenesis (Adams and Eichmann, 2010). Vasculogenesis is a process of generating vessels from endothelial precursor cells or angioblasts. This process mainly occurs in the early embryo at the vasculature development stage (Risau and Flamme, 1995; Flamme et al., 1997). In disease or injury repair situations, new vessels usually form from the existing vasculature, termed angiogenesis (Adams and Eichmann, 2010). Sprouting and splitting are two types of angiogenesis. In sprouting angiogenesis, the ECM of existing vessels is reorganized and paves ways for ECs. ECs then migrate, proliferate, generate tubules, and finally form new sprouts (Eilken and Adams, 2010). Splitting angiogenesis (or intussusception) is achieved by splitting from pre-existing vessels oppositely. New vessels then grow under the influence of growth factors, pericytes, and myofibroblasts (Gianni-Barrera et al., 2018).

Several molecules and signaling pathways participate in angiogenesis and endothelial regeneration (Tsuji-Tamura and Ogawa, 2018; Evans et al., 2021). Transcription factors, such as FoxM1 (Huang and Zhao, 2012), HIF-1 $\alpha$ (Huang et al., 2019), Sox17 (Liu et al., 2019a) Atf3 (McDonald et al., 2018), and Foxo1 (Wilhelm et al., 2016) are involved in EC proliferation. Mef2 factors regulate sprouting angiogenesis (Sacilotto et al., 2016). Foxo1 and Foxo3 inhibit the migration and tube formation of HUVEC (Potente et al., 2005). These transcription factors integrate with multiple signaling pathways to modulate angiogenesis. VEGF signaling participates in angiogenic processes in both physiological and pathological conditions (Apte et al., 2019). PI3K-Akt signaling activation enhances HIF-1 $\alpha$ production, increases VEGF expression, and promotes angiogenesis (Jiang et al., 2000, 2001). Inhibition of the PI3K-Akt and mTOR signaling pathways can activate Foxo1 and induce EC elongation (Tsuji-Tamura and Ogawa, 2016). Additionally, Notch signaling is also important during angiogenesis. Dll4, which is expressed at tip cells, can bind to and activate Notch signaling in neighboring stalk cells to modulate sprouting and branching (Hellstrom et al., 2007; Eilken and Adams, 2010).

Angiogenesis is the primary form of vascular formation in the lesion microenvironment after SCI. Triggered by hypoxia and proangiogenic growth factors, ECs undergo sprouting, proliferation, and finally remodeling (Carmeliet, 2000, 2003). It is possible that angiogenesis serves as an early scaffold for axonal regeneration across the injury site, facilitating tissue remodeling and survival (Casella et al., 2002). Blood vessel density transiently increases within 2 weeks due to endogenous angiogenesis. However, endogenous angiogenesis is insufficient to support local metabolism, accelerating hypoxic ischemia and cell death at lesion sites. Additionally, newly formed blood vessels are usually leaky with impaired BSCB (Fassbender et al., 2011). New vessels fail to associate with other cells (neurons, astrocytes, or pericytes) and do not organize into a functional vasculature (Loy et al., 2002; Ng et al., 2011). Due to their geometry and plasticity, the new vessels do not guide neighboring sprout outgrowth (Losey et al., 2014). The malfunctioning vasculature impedes self-repair at the injury site and prevents functional recovery after SCI.

\section{NEUROPROTECTIVE EFFECT OF BLOOD VESSELS}

There is a close relationship between revascularization and improved functional outcomes after SCI. First, a wellvascularized lesion provides a permissive microenvironment for local tissue survival and nerve regeneration. It has been demonstrated that improved capillary blood flow (Li et al., 2017), angiogenesis ( $\mathrm{Hu}$ et al., 2015), and BSCB integrity (Lu et al., 2019) can facilitate functional recovery after spinal cord injury. Blood vessels potentially serve as a scaffold to guide axonal sprouting after injury. Emerging evidence has shown that there are similarly attractive and repulsive cues in vascular and axonal guidance, such as Ephrins, Semaphorins, Slits, Nogo, and VEGF (Serini and Bussolino, 2004). Blood vessels and nerves interact physically and can affect each other. VEGF-A, released from neurons and glial cells, promotes vessel growth (Ferrara, 2005). Neurotrophins, such as NGF and NT-3, control the sympathetic innervation of blood vessels. Moreover, vascular cell types, such as vSMCs, secret endothelins, providing guidance cues for axons (Ieda et al., 2004). Other research has shown that ECs express a repulsive axon guidance cue termed Semaphorin 3A, which inhibits axonal growth to blood vessels (Damon, 2006). Besides neurons and axons, blood vessels also interact with other cells, including astrocytes, microglia, and oligodendrocytes. After SCI, EphA4, for example, is upregulated in astrocytes that are tightly associated with blood vessels. Silencing EphA4 decreases the tight association between astrocytes and blood vessels, impairing BSCB (Goldshmit et al., 2006). The vascular endothelium also provides a physical substrate for oligodendrocyte precursor migration (Tsai et al., 2016). Recent research indicates that microglia play a critical role in maintaining vascular integrity via fibrinogen-Mac-1 interaction (Halder and Milner, 2019).

In general, revascularization is essential for nerve repair. Therapeutic interventions for SCI can focus on the lesion vasculature. Approaches to promote angiogenesis, restore blood supply, and regain a non-leaky state vascular system as early as possible will attenuate secondary damage, limit nerve tissue loss, promote axon regeneration, and improve functional recovery after SCI.

\section{THERAPEUTIC INTERVENTIONS}

To date, researchers have conducted several therapeutic interventions based on revascularization for SCI. These treatments include proangiogenic factor administration, gene therapy, cell transplantation, biomaterial implantation, and physical stimulation, illustrated in Figure 1 and Table 1. 


\section{Proangiogenic Factor Administration}

A widely accepted vascular intervention for SCI is that of regulating angiogenic factors (Klagsbrun and Moses, 1999; Graumann et al., 2011). Vascular endothelial growth factor (VEGF), is one of the best characterized angiogenic factors, which modulate blood vessel formation, promote the proliferation and migration of ECs (Ferrara et al., 2003). VEGF treatment alone (Widenfalk et al., 2003) or in combination (Yu et al., 2016 b) increases angiogenesis and axon regrowth. Delivery of angiogenic factor fibroblast growth factor-2 (FGF2) into the lesion site elevates blood vessel density, increases blood flow rates, and decreases the permeability of BSCB. However, the improvement in axonal and functional recovery is not apparent (Kang et al., 2010, 2013).

Some hormones (melatonin, estrogen; Wu et al., 2014; Samantaray et al., 2016; Jing et al., 2017; Ni et al., 2018), enzymes, and chemical drugs also have a proangiogenic effect and are applied in SCI therapy. Chondroitinase ABC (ChABC) is widely used in SCI treatments to degrade extracellular chondroitin sulfate proteoglycans (CSPG), a primary obstacle for axon regeneration. Researchers have shown that ChABC also stimulates axonal remodeling by promoting revascularization (Milbreta et al., 2014). Cleavage of CSPG by $\mathrm{ChABC}$ affected the detachment and separation of blood vessel BM, enhancing neoangiogenesis and blood vessel maturation (Milbreta et al., 2014). MMPs create a hostile environment for SCI recovery. Treatments using flufenamic acid (FFA) or the specific MMP-8 inhibitor (MMP-8I) significantly attenuate MMP-mediated BSCB disruption (Kumar et al., 2018; Yao et al., 2018b). Colony-stimulating factor G-CSF (Kawabe et al., 2011) promotes local angiogenesis by increasing angiogenic cytokine expression.

\section{Gene Therapy}

Proangiogenic factors overexpressed by viral vectors have been shown to improve angiogenesis and enhance BSCB integrity after SCI (Kitamura et al., 2007; Herrera et al., 2010). Additionally, genes dysregulated after SCI may also be potential targets for blood vessel innervations. For example, transient receptor potential channel protein TRPV4 increases during the acute phase of SCI. TRPV4 KO mice show reduced EC damage, increased tight junction proteins, and attenuated inflammation, leading to improved neuroprotection and functional recovery (Kumar et al., 2020). Knockdown of UTX, a histone H3K27 demethylase that is upregulated in ECs after SCI, promotes EC migration and tube formation. Functional recovery is also enhanced as evaluated by BMS score, electrophysiology, tactile and temperature sensation $(\mathrm{Ni}$ et al., 2019). Mechanism analysis shows that UTX decreases promoter methylation of miR-24, which targets genes involved in angiogenesis (Ni et al., 2019).

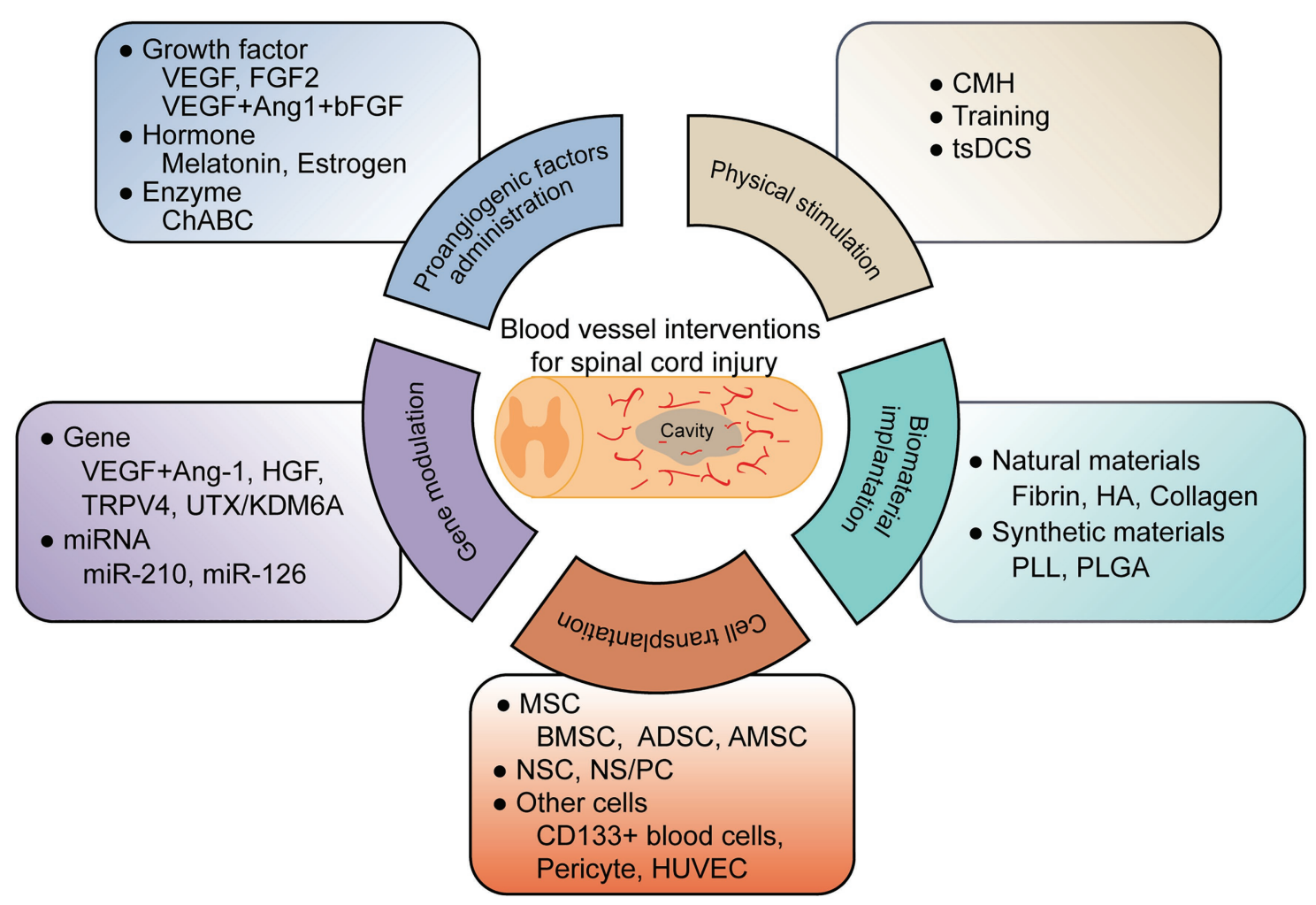

FIGURE 1 | A graphic summary of current blood vessel interventions for spinal cord injury. 
TABLE 1 | Lists of current blood vessel interventions for spinal cord injury.

\begin{tabular}{|c|c|}
\hline \multicolumn{2}{|c|}{ Proangiogenic factors administration } \\
\hline Growth factor & $\begin{array}{l}\text { VEGF(Widenfalk et al., 2003), VEGF+Ang1+bFGF (Yu et al. } \\
\text { 2016b), FGF2 (Kang et al., 2010, 2013) }\end{array}$ \\
\hline Hormone & $\begin{array}{l}\text { Melatonin (Wu et al., 2014; Jing et al., 2017), } \\
\text { Estrogen(Samantaray et al., 2016; Ni et al., 2018) }\end{array}$ \\
\hline Enzyme & ChABC (Milbreta et al., 2014) \\
\hline Others & $\begin{array}{l}\text { FFA (Yao et al., 2018b), MMP-8I (Kumar et al., 2018), } \\
\text { G-CSF (Kawabe et al., 2011) }\end{array}$ \\
\hline \multicolumn{2}{|l|}{ Gene modulation } \\
\hline Gene & $\begin{array}{l}\text { VEGF+Ang-1(Herrera et al., 2010), HGF(Kitamura et al., } \\
\text { 2007), TRPV4 (Kumar et al., 2020), UTX/KDM6A (Ni et al., } \\
\text { 2019) }\end{array}$ \\
\hline miRNA & miR-210 (Ujigo et al., 2014), miR-126 (Hu et al., 2015) \\
\hline \multicolumn{2}{|c|}{ Cell transplantation } \\
\hline MSC & $\begin{array}{l}\text { BMSC (Matsushita et al., 2015; Watanabe et al., 2015; } \\
\text { Ropper et al., 2017), ADSC (Zhou et al., 2013), umbilical } \\
\text { cord (Badner et al., 2016), AMSC (Zhou et al., 2016) }\end{array}$ \\
\hline NSC, NS/PC & $\begin{array}{l}\text { NSC(Kim et al., 2009; Lien et al., 2019), NS/PC(Kumagai } \\
\text { et al., 2009; Nori et al., 2011), NPC+EC (Rauch et al., } \\
\text { 2009) }\end{array}$ \\
\hline Other cells & $\begin{array}{l}\text { CD133+ peripheral blood cells (Fujioka et al., 2012; Sasaki } \\
\text { et al., 2009), Pericyte (Badner et al., 2016), HUVEC (Zhong } \\
\text { et al., 2020) }\end{array}$ \\
\hline \multicolumn{2}{|c|}{ Biomaterial implantation } \\
\hline Natural materials & $\begin{array}{l}\text { Fibrin (Yao et al., 2018a; Loureiro et al., 2019), HA (Wei } \\
\text { et al., 2010), Collagen (Wang et al., 2018) }\end{array}$ \\
\hline Synthetic materials & $\begin{array}{l}\text { PLL (Patist et al., 2004), PLGA (Yu et al., 2016b; Ropper } \\
\text { et al., 2017) }\end{array}$ \\
\hline \multicolumn{2}{|c|}{ Physical stimulation } \\
\hline & $\begin{array}{l}\text { CMH (Halder et al., 2018), Training (Kissane et al., 2019; } \\
\text { Ying et al., 2020, 2021), tsDCS (Samaddar et al., 2017) }\end{array}$ \\
\hline
\end{tabular}

MicroRNAs (miRNAs), such as miR-210 and miR-126, also participate in angiogenesis (Fish et al., 2008; Kir et al., 2018). Administration of miR-210 increases blood vessels at day 3 after SCI, probably by inhibiting the expression of PTP1B and EFNA3, two antiangiogenic factors in proper vascular growth (Ujigo et al., 2014). Agomir-126 treatment after SCI results in enhanced vascularity, reduced inflammation, and improved locomotor function. Mechanism analysis suggests that this angiogenic effect of miR-126 is mediated by repressing SPRED1 and PIK3R2 (Fish et al., 2008; Hu et al., 2015).

\section{Cell Transplantation}

Mesenchymal stem cells (MSCs) are capable of self-renewal and differentiation. It is an attractive cell source for cell-based therapeutic strategies (Assinck et al., 2017). Transplantation of MSCs derived from bone marrow (BMSCs; Matsushita et al., 2015; Watanabe et al., 2015; Ropper et al., 2017), adipose tissue (ADSCs; Zhou et al., 2013), umbilical cord (Badner et al., 2016), or amnion (AMSCs; Zhou et al., 2016) have shown pleiotropic positive effects on the lesion microenvironment after SCI, including increased angiogenesis and restored BSCB integrity. This probably is due to the angiogenic factor secretion by MSCs (Baraniak and McDevitt, 2010). However, there are some limitations on MSC treatments, such as insufficient reach to the lesion core and potential tumor formation ( $\mathrm{Lu}$ et al., 2019). Extracellular vesicles or exosomes derived from MSC contain paracrine-secreted angiogenic factors. They can exert the role of MSCs in neovascularization, improving SCI recovery (Kim et al., 2018; Lu et al., 2019; Huang et al., 2020).

Neural stem cells (NSCs) or neural stem/progenitor cells (NS/PCs) can differentiate into three major neuroglial lineages (neurons, astrocytes, and oligodendrocytes). Their implantation has an angiogenic effect induced by elevated VEGF expression in the injured spinal cord tissue (Kim et al., 2009; Kumagai et al., 2009; Nori et al., 2011). The astrocytic components of NSC grafts can also migrate and join endogenous astrocytes, integrating into the host BSCB (Lien et al., 2019). Co-implantation of NPCs and ECs after SCI increases functional vessel density and promotes BSCB re-establishment (Rauch et al., 2009).

Other cells, such as $\mathrm{CD}_{133^{+}}$peripheral blood cells (Sasaki et al., 2009; Fujioka et al., 2012), pericytes (Badner et al., 2016), and HUVECs (Zhong et al., 2020), also have proangiogenic effects on SCI repair. However, given the pleiotropic effects of cell transplantation on the spinal cord, improved vascular function may not be a significant cause of the observed functional recovery.

\section{Biomaterial Implantation}

Natural or synthetic biomaterials support revascularization by promoting and guiding blood vessel formation (Haggerty et al., 2018; Liu et al., 2019b). Fibrin, hyaluronic acid (HA), and collagen are natural biomaterials with intrinsic angiogenic properties. They can combine angiogenic factors to enhance vascularization after SCI (Wei et al., 2010; Wang et al., 2018; Yao et al., 2018a; Loureiro et al., 2019). Synthetic biomaterials, such as poly (L-lactic acid; PLL; Patist et al., 2004) and poly (lactic-co-glycolic) acid (PLGA; Yu et al., 2016b; Ropper et al., 2017), additionally, can provide for sustained release of pro-angiogenic factors or delivery of implanted cells to the lesion site after SCI. These applications of biomaterials in angiogenesis for SCI have recently been comprehensively reviewed (Haggerty et al., 2018).

\section{Physical Stimulation}

Treatments that induce hypoxia, a pro-angiogenic condition, also trigger the vascular remodeling response and promote vessel density after injury (Halder et al., 2018). Chronic mild hypoxia $\left(\mathrm{CMH} ; 8 \% \mathrm{O}_{2}\right.$ for up to 7 days) promotes $\mathrm{EC}$ proliferation, vascularization, and BSCB integrity through $\alpha 5 \beta 1$ integrin. Locomotor training combined with epidural stimulation, moreover, increases capillary distribution across the muscle after SCI (Kissane et al., 2019). Recently, researchers have found that water treadmill training (TT) reduces BSCB permeability after SCI by inhibiting MMP-2/9 expression (Ying et al., 2020). TT also triggers the BDNF/TrkB-CREB signaling pathway to ameliorate BSCB disruption following SCI (Ying et al., 2021). Besides, trans-spinal direct current stimulation 
(tsDCS) promotes blood flow to modulate neural cell migration and proliferation after SCI (Samaddar et al., 2017).

\section{CONCLUSION AND PERSPECTIVE}

Blood vessel vascularization and remodeling after SCI are critical for SCI repair and functional recovery. Researchers have applied numerous blood vessel interventions for SCI. However, the therapeutic effect is limited and the regulatory mechanisms are unclear. Several issues need to be addressed in further studies. First, there is the discovery of more potential genes or molecules. The vascular system and the central nervous system share many guidance molecules, such as Ephrins, Semaphorins, Slits, and Netrins. Manipulations of these genes will potentially promote vessel and axonal regeneration in SCI repair processes (Adams and Eichmann, 2010). Blood vessel interventions used in other diseases, such as stroke (Wang et al., 2004), Alzheimer's Disease (Zlokovic, 2005), or peripheral nerve injury (Sekiguchi et al., 2012), provide another choice for SCI therapy. Second, there is the determination of interactions between nervous, immune, and vascular systems. As detected by two-photon microscopy, blood vessels transiently increase and interact with neurons within 2 weeks after SCI. However, the guidance of new vessels on adjoining sprouts is inadequate (Dray et al., 2009). Inflammation responses also regulate

\section{REFERENCES}

Adams, R. H., and Eichmann, A. (2010). Axon guidance molecules in vascular patterning. Cold Spring Harb. Perspect. Biol. 2:a001875. doi: 10.1101/cshperspect. a001875

Apte, R. S., Chen, D. S., and Ferrara, N. (2019). VEGF in signaling and disease: beyond discovery and development. Cell 176, 1248-1264. doi: 10.1016/j.cell.2019.01.021

Assinck, P., Duncan, G. J., Hilton, B. J., Plemel, J. R., and Tetzlaff, W. (2017). Cell transplantation therapy for spinal cord injury. Nat. Neurosci. 20, 637-647. doi: 10.1038/nn.4541

Badner, A., Vawda, R., Laliberte, A., Hong, J., Mikhail, M., Jose, A., et al. (2016). Early intravenous delivery of human brain stromal cells modulates systemic inflammation and leads to vasoprotection in traumatic spinal cord injury. Stem Cells Transl. Med. 5, 991-1003. doi: 10.5966/sctm.2015-0295

Baraniak, P. R., and McDevitt, T. C. (2010). Stem cell paracrine actions and tissue regeneration. Regen. Med. 5, 121-143. doi: 10.2217/rme.09.74

Carmeliet, P. (2000). Mechanisms of angiogenesis and arteriogenesis. Nat. Med. 6, 389-395. doi: 10.1038/74651

Carmeliet, P. (2003). Angiogenesis in health and disease. Nat. Med. 9, 653-660. doi: $10.1038 / \mathrm{nm} 0603-653$

Casella, G. T., Marcillo, A., Bunge, M. B., and Wood, P. M. (2002). New vascular tissue rapidly replaces neural parenchyma and vessels destroyed by a contusion injury to the rat spinal cord. Exp. Neurol. 173, 63-76. doi: 10.1006/exnr.2001.7827

Damon, D. H. (2006). Vascular endothelial-derived semaphorin 3 inhibits sympathetic axon growth. Am. J. Physiol. Heart Circ. Physiol. 290, H1220-H1225. doi: 10.1152/ajpheart.01232.2004

Donnelly, D. J., and Popovich, P. G. (2008). Inflammation and its role in neuroprotection, axonal regeneration and functional recovery after spinal cord injury. Exp. Neurol. 209, 378-388. doi: 10.1016/j.expneurol.2007.06.009

Dray, C., Rougon, G., and Debarbieux, F. (2009). Quantitative analysis by in vivo imaging of the dynamics of vascular and axonal networks in injured mouse spinal cord. Proc. Natl. Acad. Sci. U. S. A. 106, 9459-9464. doi: 10.1073/ pnas.0900222106 angiogenesis during tissue regeneration (Donnelly and Popovich, 2008). Macrophages can secrete factors to promote tip-endothelial cell fusion, remodel the basal membrane, and attract pericytes or vSMCs for revascularization (Haggerty et al., 2018). Finally, there is the identification of combined strategies for revascularization. As summarized, we can conduct blood vessel interventions for SCI by proangiogenic factor administration, gene modulation, cell transplantation, biomaterial implantation, and physical stimulation. Multiple strategy integration might strengthen the proangiogenic effects, restore BSCB, and overcome delivery limitations.

\section{AUTHOR CONTRIBUTIONS}

$\mathrm{CY}$ and XC wrote the manuscript. CY and BY reviewed the manuscript. All authors contributed to the article and approved the submitted version.

\section{FUNDING}

This work was supported by the National Major Project of Research and Development (2017YFA0104701) and Jiangsu Association of Science and Technology Youth Science and Technology Talents Enrollment Project.

Eilken, H. M., and Adams, R. H. (2010). Dynamics of endothelial cell behavior in sprouting angiogenesis. Curr. Opin. Cell Biol. 22, 617-625. doi: 10.1016/j. ceb.2010.08.010

Evans, C. E., Iruela-Arispe, M. L., and Zhao, Y. Y. (2021). Mechanisms of endothelial regeneration and vascular repair and their application to regenerative medicine. Am. J. Pathol. 191, 52-65. doi: 10.1016/j.ajpath.2020.10.001

Fassbender, J. M., Whittemore, S. R., and Hagg, T. (2011). Targeting microvasculature for neuroprotection after SCI. Neurotherapeutics 8, 240-251. doi: 10.1007/s13311-011-0029-1

Ferrara, N. (2005). The role of VEGF in the regulation of physiological and pathological angiogenesis. EXS. 94, 209-231. doi: 10.1007/3-7643-7311-3_15

Ferrara, N., Gerber, H. P., and LeCouter, J. (2003). The biology of VEGF and its receptors. Nat. Med. 9, 669-676. doi: 10.1038/nm0603-669

Figley, S. A., Khosravi, R., Legasto, J. M., Tseng, Y. F., and Fehlings, M. G. (2014). Characterization of vascular disruption and blood-spinal cord barrier permeability following traumatic spinal cord injury. J. Neurotrauma 31, 541-552. doi: 10.1089/neu.2013.3034

Fish, J. E., Santoro, M. M., Morton, S. U., Yu, S., Yeh, R. F., Wythe, J. D., et al. (2008). miR-126 regulates angiogenic signaling and vascular integrity. Dev. Cell 15, 272-284. doi: 10.1016/j.devcel.2008.07.008

Flamme, I., Frolich, T., and Risau, W. (1997). Molecular mechanisms of vasculogenesis and embryonic angiogenesis. J. Cell. Physiol. 173, 206-210. doi: 10.1002/(SICI)1097-4652(199711)173:2<206::AID-JCP22>3.0.CO;2-C

Fleming, J. C., Norenberg, M. D., Ramsay, D. A., Dekaban, G. A., Marcillo, A. E., Saenz, A. D., et al. (2006). The cellular inflammatory response in human spinal cords after injury. Brain J. Neurol. 129, 3249-3269. doi: 10.1093/brain/awl296

Fujioka, Y., Tanaka, N., Nakanishi, K., Kamei, N., Nakamae, T., Izumi, B., et al. (2012). Magnetic field-based delivery of human CD133(+) cells promotes functional recovery after rat spinal cord injury. Spine 37, E768-E777. doi: 10.1097/BRS.0b013e318246d59c

Garcia, E., Aguilar-Cevallos, J., Silva-Garcia, R., and Ibarra, A. (2016). Cytokine and growth factor activation in vivo and in vitro after spinal cord injury. Mediat. Inflamm. 2016:9476020. doi: 10.1155/2016/9476020

Gianni-Barrera, R., Butschkau, A., Uccelli, A., Certelli, A., Valente, P., Bartolomeo, M., et al. (2018). PDGF-BB regulates splitting angiogenesis in 
skeletal muscle by limiting VEGF-induced endothelial proliferation. Angiogenesis 21, 883-900. doi: 10.1007/s10456-018-9634-5

Goldshmit, Y., Galea, M. P., Bartlett, P. F., and Turnley, A. M. (2006). EphA4 regulates central nervous system vascular formation. J. Comp. Neurol. 497, 864-875. doi: 10.1002/cne.21029

Graumann, U., Ritz, M. F., and Hausmann, O. (2011). Necessity for revascularization after spinal cord injury and the search for potential therapeutic options. Curr. Neurovasc. Res. 8, 334-341. doi: 10.2174/156720211798121007

Guha, A., Tator, C. H., and Rochon, J. (1989). Spinal cord blood flow and systemic blood pressure after experimental spinal cord injury in rats. Stroke 20, 372-377. doi: 10.1161/01.STR.20.3.372

Hagg, T., and Oudega, M. (2006). Degenerative and spontaneous regenerative processes after spinal cord injury. J. Neurotrauma 23, 264-280. doi: 10.1089/ neu.2006.23.263

Haggerty, A. E., Maldonado-Lasuncion, I., and Oudega, M. (2018). Biomaterials for revascularization and immunomodulation after spinal cord injury. Biomed. Mater. 13:044105. doi: 10.1088/1748-605X/aaa9d8

Halder, S. K., Kant, R., and Milner, R. (2018). Chronic mild hypoxia promotes profound vascular remodeling in spinal cord blood vessels, preferentially in white matter, via an alpha5betal integrin-mediated mechanism. Angiogenesis 21, 251-266. doi: 10.1007/s10456-017-9593-2

Halder, S. K., and Milner, R. (2019). A critical role for microglia in maintaining vascular integrity in the hypoxic spinal cord. Proc. Natl. Acad. Sci. U. S. A. 116, 26029-26037. doi: 10.1073/pnas.1912178116

Hellstrom, M., Phng, L. K., Hofmann, J. J., Wallgard, E., Coultas, L., Lindblom, P., et al. (2007). Dll4 signalling through Notch1 regulates formation of tip cells during angiogenesis. Nature 445, 776-780. doi: 10.1038/nature05571

Herrera, J. J., Sundberg, L. M., Zentilin, L., Giacca, M., and Narayana, P. A. (2010). Sustained expression of vascular endothelial growth factor and angiopoietin-1 improves blood-spinal cord barrier integrity and functional recovery after spinal cord injury. J. Neurotrauma 27, 2067-2076. doi: 10.1089/ neu. 2010.1403

Himmels, P., Paredes, I., Adler, H., Karakatsani, A., Luck, R., Marti, H. H., et al. (2017). Motor neurons control blood vessel patterning in the developing spinal cord. Nat. Commun. 8:14583. doi: 10.1038/ncomms14583

Hu, J., Zeng, L., Huang, J., Wang, G., and Lu, H. (2015). miR-126 promotes angiogenesis and attenuates inflammation after contusion spinal cord injury in rats. Brain Res. 1608, 191-202. doi: 10.1016/j.brainres.2015.02.036

Huang, J. H., Xu, Y., Yin, X. M., and Lin, F. Y. (2020). Exosomes derived from miR-126-modified MSCs promote angiogenesis and neurogenesis and attenuate apoptosis after spinal cord injury in rats. Neuroscience 424, 133-145. doi: 10.1016/j.neuroscience.2019.10.043

Huang, X., Zhang, X., Zhao, D. X., Yin, J., Hu, G., Evans, C. E., et al. (2019). Endothelial hypoxia-inducible factor-1alpha is required for vascular repair and resolution of inflammatory lung injury through forkhead box protein M1. Am. J. Pathol. 189, 1664-1679. doi: 10.1016/j.ajpath.2019.04.014

Huang, X. J., and Zhao, Y. Y. (2012). Transgenic expression of FoxM1 promotes endothelial repair following lung injury induced by polymicrobial sepsis in mice. PLoS One 7:e50094. doi: 10.1371/journal.pone.0052576

Huber, J. D., Egleton, R. D., and Davis, T. P. (2001). Molecular physiology and pathophysiology of tight junctions in the blood-brain barrier. Trends Neurosci. 24, 719-725. doi: 10.1016/S0166-2236(00)02004-X

Hutson, T. H., and Di Giovanni, S. (2019). The translational landscape in spinal cord injury: focus on neuroplasticity and regeneration. Nat. Rev. Neurol. 15, 732-745. doi: 10.1038/s41582-019-0280-3

Ieda, M., Fukuda, K., Hisaka, Y., Kimura, K., Kawaguchi, H., Fujita, J., et al. (2004). Endothelin-1 regulates cardiac sympathetic innervation in the rodent heart by controlling nerve growth factor expression. J. Clin. Invest. 113, 876-884. doi: 10.1172/JCI200419480

Jiang, B. H., Jiang, G., Zheng, J. Z., Lu, Z., Hunter, T., and Vogt, P. K. (2001). Phosphatidylinositol 3-kinase signaling controls levels of hypoxia-inducible factor 1. Cell Growth Differ. 12, 363-369.

Jiang, B. H., Zheng, J. Z., Aoki, M., and Vogt, P. K. (2000). Phosphatidylinositol 3-kinase signaling mediates angiogenesis and expression of vascular endothelial growth factor in endothelial cells. Proc. Natl. Acad. Sci. U. S. A. 97, 1749-1753.

Jin, L. Y., Li, J., Wang, K. F., Xia, W. W., Zhu, Z. Q., Wang, C. R., et al. (2021). Blood-spinal cord barrier in spinal cord injury: a review. J. Neurotrauma. doi: 10.1089/neu.2020.7413 [Epub ahead of print]
Jing, Y., Bai, F., Chen, H., and Dong, H. (2017). Melatonin prevents blood vessel loss and neurological impairment induced by spinal cord injury in rats. J. Spinal Cord Med. 40, 222-229. doi: 10.1080/10790268.2016.1227912

Kang, C. E., Baumann, M. D., Tator, C. H., and Shoichet, M. S. (2013). Localized and sustained delivery of fibroblast growth factor-2 from a nanoparticlehydrogel composite for treatment of spinal cord injury. Cells Tissues Organs 197, 55-63. doi: 10.1159/000339589

Kang, C. E., Clarkson, R., Tator, C. H., Yeung, I. W., and Shoichet, M. S. (2010). Spinal cord blood flow and blood vessel permeability measured by dynamic computed tomography imaging in rats after localized delivery of fibroblast growth factor. J. Neurotrauma 27, 2041-2053. doi: 10.1089/neu.2010.1345

Kawabe, J., Koda, M., Hashimoto, M., Fujiyoshi, T., Furuya, T., Endo, T., et al. (2011). Neuroprotective effects of granulocyte colony-stimulating factor and relationship to promotion of angiogenesis after spinal cord injury in rats: laboratory investigation. J. Neurosurg. Spine 15, 414-421. doi: 10.3171/ 2011.5.SPINE10421

Kim, H. M., Hwang, D. H., Lee, J. E., Kim, S. U., and Kim, B. G. (2009). Ex vivo VEGF delivery by neural stem cells enhances proliferation of glial progenitors, angiogenesis, and tissue sparing after spinal cord injury. PLoS One 4:e4987. doi: 10.1371/journal.pone.0008455

Kim, H. Y., Kumar, H., Jo, M. J., Kim, J., Yoon, J. K., Lee, J. R., et al. (2018). Therapeutic efficacy-potentiated and diseased organ-targeting nanovesicles derived from mesenchymal stem cells for spinal cord injury treatment. Nano Lett. 18, 4965-4975. doi: 10.1021/acs.nanolett.8b01816

Kir, D., Schnettler, E., Modi, S., and Ramakrishnan, S. (2018). Regulation of angiogenesis by microRNAs in cardiovascular diseases. Angiogenesis 21, 699-710. doi: 10.1007/s10456-018-9632-7

Kissane, R. W. P., Wright, O., Al'Joboori, Y. D., Marczak, P., Ichiyama, R. M., and Egginton, S. (2019). Effects of treadmill training on microvascular remodeling in the rat after spinal cord injury. Muscle Nerve 59, 370-379. doi: $10.1002 /$ mus.26379

Kitamura, K., Iwanami, A., Nakamura, M., Yamane, J., Watanabe, K., Suzuki, Y., et al. (2007). Hepatocyte growth factor promotes endogenous repair and functional recovery after spinal cord injury. J. Neurosci. Res. 85, 2332-2342. doi: $10.1002 /$ jnr.21372

Klagsbrun, M., and Moses, M. A. (1999). Molecular angiogenesis. Chem. Biol. 6, R217-R224. doi: 10.1016/S1074-5521(99)80081-7

Kumagai, G., Okada, Y., Yamane, J., Nagoshi, N., Kitamura, K., Mukaino, M., et al. (2009). Roles of ES cell-derived gliogenic neural stem/progenitor cells in functional recovery after spinal cord injury. PLoS One 4:e7706. doi: 10.1371/journal.pone.0007706

Kumar, H., Jo, M. J., Choi, H., Muttigi, M. S., Shon, S., Kim, B. J., et al. (2018). Matrix metalloproteinase-8 inhibition prevents disruption of bloodspinal cord barrier and attenuates inflammation in rat model of spinal cord injury. Mol. Neurobiol. 55, 2577-2590. doi: 10.1007/s12035-017-0509-3

Kumar, H., Lim, C. S., Choi, H., Joshi, H. P., Kim, K. T., Kim, Y. H., et al. (2020). Elevated TRPV4 levels contribute to endothelial damage and scarring in experimental spinal cord injury. J. Neurosci. 40, 1943-1955. doi: 10.1523/ JNEUROSCI.2035-19.2020

Li, Y., Lucas-Osma, A. M., Black, S., Bandet, M. V., Stephens, M. J., Vavrek, R., et al. (2017). Pericytes impair capillary blood flow and motor function after chronic spinal cord injury. Nat. Med. 23, 733-741. doi: 10.1038/nm.4331

Lien, B. V., Tuszynski, M. H., and Lu, P. (2019). Astrocytes migrate from human neural stem cell grafts and functionally integrate into the injured rat spinal cord. Exp. Neurol. 314, 46-57. doi: 10.1016/j.expneurol.2019.01.006

Liu, S., Xie, Y. Y., and Wang, B. (2019b). Role and prospects of regenerative biomaterials in the repair of spinal cord injury. Neural Regen. Res. 14, 1352-1363. doi: 10.4103/1673-5374.253512

Liu, M. L., Zhang, L. H., Marsboom, G., Jambusaria, A., Xiong, S. Q., Toth, P. T., et al. (2019a). Sox17 is required for endothelial regeneration following inflammation-induced vascular injury. Nat. Commun. 10:2126. doi: 10.1038/ s41467-019-10134-y

Losey, P., Young, C., Krimholtz, E., Bordet, R., and Anthony, D. C. (2014). The role of hemorrhage following spinal-cord injury. Brain Res. 1569, 9-18. doi: 10.1016/j.brainres.2014.04.033

Loureiro, J., Torres, A. L., Neto, T., Aguiar, P., Barrias, C. C., Pinto, M. T., et al. (2019). Conjugation of the T1 sequence from CCN1 to fibrin hydrogels for therapeutic vascularization. Mater. Sci. Eng. C Mater. Biol. Appl. 104:109847. doi: 10.1016/j.msec.2019.109847 
Loy, D. N., Crawford, C. H., Darnall, J. B., Burke, D. A., Onifer, S. M., and Whittemore, S. R. (2002). Temporal progression of angiogenesis and basal lamina deposition after contusive spinal cord injury in the adult rat. $J$. Comp. Neurol. 445, 308-324. doi: 10.1002/cne.10168

Lu, Y., Zhou, Y., Zhang, R., Wen, L., Wu, K., Li, Y., et al. (2019). Bone mesenchymal stem cell-derived extracellular vesicles promote recovery following spinal cord injury via improvement of the integrity of the blood-spinal cord barrier. Front. Neurosci. 13:209. doi: 10.3389/fnins.2019.00209

Martirosyan, N. L., Feuerstein, J. S., Theodore, N., Cavalcanti, D. D., Spetzler, R. F., and Preul, M. C. (2011). Blood supply and vascular reactivity of the spinal cord under normal and pathological conditions. J. Neurosurg. Spine 15, 238-251. doi: 10.3171/2011.4.SPINE10543

Matsushita, T., Lankford, K. L., Arroyo, E. J., Sasaki, M., Neyazi, M., Radtke, C., et al. (2015). Diffuse and persistent blood-spinal cord barrier disruption after contusive spinal cord injury rapidly recovers following intravenous infusion of bone marrow mesenchymal stem cells. Exp. Neurol. 267, 152-164. doi: 10.1016/j.expneurol.2015.03.001

McDonald, A. I., Shirali, A. S., Aragon, R., Ma, F. Y., Hernandez, G., Vaughn, D. A., et al. (2018). Endothelial regeneration of large vessels is a biphasic process driven by local cells with distinct proliferative capacities. Cell Stem Cell 23, 210-225.e6. doi: 10.1016/j.stem.2018.07.011

Milbreta, U., von Boxberg, Y., Mailly, P., Nothias, F., and Soares, S. (2014). Astrocytic and vascular remodeling in the injured adult rat spinal cord after chondroitinase ABC treatment. J. Neurotrauma 31, 803-818. doi: 10.1089/ neu.2013.3143

Ng, M. T., Stammers, A. T., and Kwon, B. K. (2011). Vascular disruption and the role of angiogenic proteins after spinal cord injury. Transl. Stroke Res. 2, 474-491. doi: 10.1007/s12975-011-0109-x

Ni, S., Cao, Y., Jiang, L., Luo, Z., Lu, H., Hu, J., et al. (2018). Synchrotron radiation imaging reveals the role of estrogen in promoting angiogenesis after acute spinal cord injury in rats. Spine 43, 1241-1249. doi: 10.1097/ BRS. 0000000000002629

Ni, S., Luo, Z., Jiang, L., Guo, Z., Li, P., Xu, X., et al. (2019). UTX/KDM6A deletion promotes recovery of spinal cord injury by epigenetically regulating vascular regeneration. Mol. Ther. 27, 2134-2146. doi: 10.1016/j. ymthe.2019.08.009

Nori, S., Okada, Y., Yasuda, A., Tsuji, O., Takahashi, Y., Kobayashi, Y., et al. (2011). Grafted human-induced pluripotent stem-cell-derived neurospheres promote motor functional recovery after spinal cord injury in mice. Proc. Natl. Acad. Sci. U. S. A. 108, 16825-16830. doi: 10.1073/ pnas. 1108077108

Oudega, M. (2012). Molecular and cellular mechanisms underlying the role of blood vessels in spinal cord injury and repair. Cell Tissue Res. 349, 269-288. doi: 10.1007/s00441-012-1440-6

Patist, C. M., Mulder, M. B., Gautier, S. E., Maquet, V., Jerome, R., and Oudega, M. (2004). Freeze-dried poly(D,L-lactic acid) macroporous guidance scaffolds impregnated with brain-derived neurotrophic factor in the transected adult rat thoracic spinal cord. Biomaterials 25, 1569-1582. doi: 10.1016/ S0142-9612(03)00503-9

Potente, M., Urbich, C., Sasaki, K., Hofmann, W. K., Heeschen, C., Aicher, A., et al. (2005). Involvement of Foxo transcription factors in angiogenesis and postnatal neovascularization. J. Clin. Invest. 115, 2382-2392. doi: 10.1172/ JCI23126

Rauch, M. F., Hynes, S. R., Bertram, J., Redmond, A., Robinson, R., Williams, C., et al. (2009). Engineering angiogenesis following spinal cord injury: a coculture of neural progenitor and endothelial cells in a degradable polymer implant leads to an increase in vessel density and formation of the bloodspinal cord barrier. Eur. J. Neurosci. 29, 132-145. doi: 10.1111/j.1460-9568. 2008.06567.x

Risau, W., and Flamme, I. (1995). Vasculogenesis. Annu. Rev. Cell Dev. Biol. 11, 73-91. doi: 10.1146/annurev.cb.11.110195.000445

Ropper, A. E., Thakor, D. K., Han, I., Yu, D., Zeng, X., Anderson, J. E., et al. (2017). Defining recovery neurobiology of injured spinal cord by synthetic matrix-assisted hMSC implantation. Proc. Natl. Acad. Sci. U. S. A. 114, E820-E829. doi: 10.1073/pnas.1616340114

Sacilotto, N., Chouliaras, K. M., Nikitenko, L. L., Lu, Y. W., Fritzsche, M., Wallace, M. D., et al. (2016). MEF2 transcription factors are key regulators of sprouting angiogenesis. Genes Dev. 30, 2297-2309. doi: 10.1101/ gad.290619.116
Samaddar, S., Vazquez, K., Ponkia, D., Toruno, P., Sahbani, K., Begum, S., et al. (2017). Transspinal direct current stimulation modulates migration and proliferation of adult newly born spinal cells in mice. J. Appl. Physiol. 122, 339-353. doi: 10.1152/japplphysiol.00834.2016

Samantaray, S., Das, A., Matzelle, D. C., Yu, S. P., Wei, L., Varma, A., et al. (2016). Administration of low dose estrogen attenuates persistent inflammation, promotes angiogenesis, and improves locomotor function following chronic spinal cord injury in rats. J. Neurochem. 137, 604-617. doi: $10.1111 /$ jnc. 13610

Sasaki, H., Ishikawa, M., Tanaka, N., Nakanishi, K., Kamei, N., Asahara, T., et al. (2009). Administration of human peripheral blood-derived CD133+ cells accelerates functional recovery in a rat spinal cord injury model. Spine 34, 249-254. doi: 10.1097/BRS.0b013e3181913cde

Sekiguchi, H., Ii, M., Jujo, K., Renault, M. A., Thorne, T., Clarke, T., et al. (2012). Estradiol triggers sonic-hedgehog-induced angiogenesis during peripheral nerve regeneration by downregulating hedgehog-interacting protein. Lab. Invest. 92, 532-542. doi: 10.1038/labinvest.2012.6

Serini, G., and Bussolino, F. (2004). Common cues in vascular and axon guidance. Physiology 19, 348-354. doi: 10.1152/physiol.00021.2004

Sharma, H. S. (2005). Pathophysiology of blood-spinal cord barrier in traumatic injury and repair. Curr. Pharm. Des. 11, 1353-1389. doi: 10.2174/1381 612053507837

Silva, N. A., Sousa, N., Reis, R. L., and Salgado, A. J. (2014). From basics to clinical: a comprehensive review on spinal cord injury. Prog. Neurobiol. 114, 25-57. doi: 10.1016/j.pneurobio.2013.11.002

Takigawa, T., Yonezawa, T., Yoshitaka, T., Minaguchi, J., Kurosaki, M., Tanaka, M., et al. (2010). Separation of the perivascular basement membrane provides a conduit for inflammatory cells in a mouse spinal cord injury model. $J$. Neurotrauma 27, 739-751. doi: 10.1089/neu.2009.1111

Tator, C. H., and Koyanagi, I. (1997). Vascular mechanisms in the pathophysiology of human spinal cord injury. J. Neurosurg. 86, 483-492. doi: 10.3171/ jns.1997.86.3.0483

Tran, A. P., Warren, P. M., and Silver, J. (2018). The biology of regeneration failure and success after spinal cord injury. Physiol. Rev. 98, 881-917. doi: 10.1152/physrev.00017.2017

Tsai, H. H., Niu, J., Munji, R., Davalos, D., Chang, J., Zhang, H., et al. (2016). Oligodendrocyte precursors migrate along vasculature in the developing nervous system. Science 351, 379-384. doi: 10.1126/science.aad3839

Tsuji-Tamura, K., and Ogawa, M. (2016). Inhibition of the PI3K-Akt and mTORC1 signaling pathways promotes the elongation of vascular endothelial cells. J. Cell Sci. 129, 1165-1178. doi: 10.1242/jcs.178434

Tsuji-Tamura, K., and Ogawa, M. (2018). Morphology regulation in vascular endothelial cells. Inflamm. Regen. 38:25. doi: 10.1186/s41232-018-0083-8

Ujigo, S., Kamei, N., Hadoush, H., Fujioka, Y., Miyaki, S., Nakasa, T., et al. (2014). Administration of microRNA-210 promotes spinal cord regeneration in mice. Spine 39, 1099-1107. doi: 10.1097/BRS.0000000000000356

Wang, L., Shi, Q., Dai, J., Gu, Y., Feng, Y., and Chen, L. (2018). Increased vascularization promotes functional recovery in the transected spinal cord rats by implanted vascular endothelial growth factor-targeting collagen scaffold. J. Orthop. Res. 36, 1024-1034. doi: 10.1002/jor.23678

Wang, L., Zhang, Z., Wang, Y., Zhang, R., and Chopp, M. (2004). Treatment of stroke with erythropoietin enhances neurogenesis and angiogenesis and improves neurological function in rats. Stroke 35, 1732-1737. doi: 10.1161/01. STR.0000132196.49028.a4

Watanabe, S., Uchida, K., Nakajima, H., Matsuo, H., Sugita, D., Yoshida, A., et al. (2015). Early transplantation of mesenchymal stem cells after spinal cord injury relieves pain hypersensitivity through suppression of pain-related signaling cascades and reduced inflammatory cell recruitment. Stem Cells 33, 1902-1914. doi: 10.1002/stem.2006

Wei, Y. T., He, Y., Xu, C. L., Wang, Y., Liu, B. F., Wang, X. M., et al. (2010). Hyaluronic acid hydrogel modified with nogo-66 receptor antibody and poly-L-lysine to promote axon regrowth after spinal cord injury. J. Biomed. Mater. Res. B Appl. Biomater. 95, 110-117. doi: 10.1002/jbm.b.31689

Whetstone, W. D., Hsu, J. Y., Eisenberg, M., Werb, Z., and Noble-Haeusslein, L. J. (2003). Blood-spinal cord barrier after spinal cord injury: relation to revascularization and wound healing. J. Neurosci. Res. 74, 227-239. doi: 10.1002/jnr.10759

Widenfalk, J., Lipson, A., Jubran, M., Hofstetter, C., Ebendal, T., Cao, Y., et al. (2003). Vascular endothelial growth factor improves functional outcome and 
decreases secondary degeneration in experimental spinal cord contusion injury. Neuroscience 120, 951-960. doi: 10.1016/S0306-4522(03)00399-3

Wilhelm, K., Happel, K., Eelen, G., Schoors, S., Oellerich, M. F., Lim, R., et al. (2016). FOXO1 couples metabolic activity and growth state in the vascular endothelium. Nature 529, 216-220. doi: 10.1038/nature16498

Wu, Q., Jing, Y., Yuan, X., Zhang, X., Li, B., Liu, M., et al. (2014). Melatonin treatment protects against acute spinal cord injury-induced disruption of blood spinal cord barrier in mice. J. Mol. Neurosci. 54, 714-722. doi: 10.1007/ s12031-014-0430-4

Yao, Y., Xu, J., Yu, T., Chen, Z., Xiao, Z., Wang, J., et al. (2018b). Flufenamic acid inhibits secondary hemorrhage and BSCB disruption after spinal cord injury. Theranostics 8, 4181-4198. doi: 10.7150/thno.25707

Yao, S., Yu, S., Cao, Z., Yang, Y., Yu, X., Mao, H. Q., et al. (2018a). Hierarchically aligned fibrin nanofiber hydrogel accelerated axonal regrowth and locomotor function recovery in rat spinal cord injury. Int. J. Nanomedicine 13, 2883-2895. doi: 10.2147/IJN.S159356

Ying, X., Xie, Q., Li, S., Yu, X., Zhou, K., Yue, J., et al. (2020). Water treadmill training attenuates blood-spinal cord barrier disruption in rats by promoting angiogenesis and inhibiting matrix metalloproteinase-2/9 expression following spinal cord injury. Fluids Barriers CNS 17:70. doi: 10.1186/s12987-020-00232-1

Ying, X., Xie, Q., Yu, X., Li, S., Wu, Q., Chen, X., et al. (2021). Water treadmill training protects the integrity of the blood-spinal cord barrier following SCI via the BDNF/TrkB-CREB signalling pathway. Neurochem. Int. 143:104945. doi: 10.1016/j.neuint.2020.104945

Yu, Q., Huang, J., Hu, J., and Zhu, H. (2016a). Advance in spinal cord ischemia reperfusion injury: blood-spinal cord barrier and remote ischemic preconditioning. Life Sci. 154, 34-38. doi: 10.1016/j.lfs.2016.03.046
Yu, S., Yao, S., Wen, Y., Wang, Y., Wang, H., and Xu, Q. (2016b). Angiogenic microspheres promote neural regeneration and motor function recovery after spinal cord injury in rats. Sci. Rep. 6:33428. doi: 10.1038/srep33428

Zhong, J., Xu, J., Lu, S., Wang, Z., Zheng, Y., Tang, Q., et al. (2020). A prevascularization strategy using novel fibrous porous silk scaffolds for tissue regeneration in mice with spinal cord injury. Stem Cells Dev. 29, 714-727. doi: $10.1089 /$ scd.2019.0199

Zhou, Z., Chen, Y., Zhang, H., Min, S., Yu, B., He, B., et al. (2013). Comparison of mesenchymal stromal cells from human bone marrow and adipose tissue for the treatment of spinal cord injury. Cytotherapy 15, 434-448. doi: 10.1016/j. jcyt.2012.11.015

Zhou, H. L., Zhang, X. J., Zhang, M. Y., Yan, Z. J., Xu, Z. M., and Xu, R. X. (2016). Transplantation of human amniotic mesenchymal stem cells promotes functional recovery in a rat model of traumatic spinal cord injury. Neurochem. Res. 41, 2708-2718. doi: 10.1007/s11064-016-1987-9

Zlokovic, B. V. (2005). Neurovascular mechanisms of Alzheimer's neurodegeneration. Trends Neurosci. 28, 202-208. doi: 10.1016/j.tins.2005.02.001

Conflict of Interest: The authors declare that the research was conducted in the absence of any commercial or financial relationships that could be construed as a potential conflict of interest.

Copyright (c) 2021 Yao, Cao and Yu. This is an open-access article distributed under the terms of the Creative Commons Attribution License (CC BY). The use, distribution or reproduction in other forums is permitted, provided the original author(s) and the copyright owner(s) are credited and that the original publication in this journal is cited, in accordance with accepted academic practice. No use, distribution or reproduction is permitted which does not comply with these terms. 